Proceedings of the

International Geometry Center

Vol. 11, no. 2 (2018) pp. 48-53

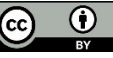

Vol. 11, no. 2 (2018) pp. $48-53$

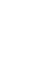

\title{
Moyal and Rankin-Cohen deformations of algebras
}

\author{
Volodymyr Lyubashenko
}

\begin{abstract}
It is proven that Rankin-Cohen brackets form an associative deformation of the algebra of polynomials whose coefficients are holomorphic functions on the upper half-plane.
\end{abstract}

Анотація. Будується вкладення добутку верхньої напівплощини на комплексну площину з виколотим нулем в комплексний простір $\mathbb{C}^{2}$ з координатами $(q, p)$. Уздовж нього переноситься бівекторне поле

$$
M=\partial_{p} \otimes \partial_{q}-\partial_{q} \otimes \partial_{p},
$$

двоїсте до стандартної симпліціальної форми на $\mathbb{C}^{2}$. Подібним чином 3 деформації Муаяля алгебри поліномів від двох змінних отримано асоціативну деформацію алгебри поліномів, коефіцієнти яких є голоморфними функціями на верхній напівплощині. Мета і основний результат: доведено, що $n$-й член цієї деформації збігається з $n$-ю дужкою Ранкіна-Коена. Це пов'язує деформацію з модулярними формами. В доведенні використовується результат Ель Градекі про єдиність з точністю до числового множника $S L(2, \mathbb{R})$-еквіваріантного бідиференціального оператора на просторах голоморфних функцій на верхній напівплощині з певною дією групи $S L(2, \mathbb{R})$. Як члени згаданої деформації, так і дужки РанкінаКоена задовольняють ці умови, отже, є пропорційними. Перевіряється, що коефіцієнт пропорційності дорівнює 1. Наведене доведення основного твердження коротше за існуючі: П. Коен, Маніна і Загіра; Конна і Московічі; В. Овсієнка.

Аннотация. Доказано, что скобки Ранкина-Коэна образуют ассоциативную деформацию алгебры многочленов, коэффициенты которых являются голоморфными функциями на верхней полуплоскости.

2010 Mathematics Subject Classification: 16S80, 32A10

Keywords: Rankin-Cohen brackets, deformation 


\section{RANKIN-COHEN BRACKETS}

Denote $\mathbb{H}=\{z \in \mathbb{C} \mid \operatorname{Im} z>0\}, \mathbb{C}^{\times}=\mathbb{C}-\{0\}$. Then the left action

$$
S L(2, \mathbb{R}) \times\left(\mathbb{H} \times \mathbb{C}^{\times}\right) \rightarrow \mathbb{H} \times \mathbb{C}^{\times}, \quad \gamma \cdot(z, X)=\left(\frac{a z+b}{c z+d}, \frac{X}{c z+d}\right),
$$

where $\gamma=\left(\begin{array}{ll}a & b \\ c & d\end{array}\right)$, induces the right action of $S L(2, \mathbb{R})$ on the algebra of holomorphic functions $\mathcal{H o l}\left(\mathbb{H} \times \mathbb{C}^{\times}\right)$. The restriction of this action to the subspace $X^{k} \mathcal{H o l}(\mathbb{H}), k \in \mathbb{Z}$, equips $\mathcal{H o l}(\mathbb{H})$ with the right action $\left.\right|_{k}$ of $S L(2, \mathbb{R})$. Recall that a modular (automorphic) form of weight $k$ [10, Definition 2.1] is, in particular, a fixed point of this action. Rankin described in $[8] S L(2, \mathbb{R})$ invariant polydifferential operators on $\mathbb{H}$. Earlier Gordan proposed bidifferential $S L(2, \mathbb{R})$-invariant operators and called them transvectants [6]. In modular form theory these operators are known as Rankin-Cohen brackets. They were defined by $\mathrm{H}$. Cohen as follows in [1]. Let $k, l \in \mathbb{Z}, n \in \mathbb{N}=\mathbb{Z} \geqslant 0$, $f, g \in \mathcal{H o l}(\mathbb{H})$. Then

$$
\left[X^{k} f, X^{l} g\right]_{n}^{R C}=X^{k+l+2 n} \sum_{r+s=n}^{r, s \geqslant 0}(-1)^{s}\left(\begin{array}{c}
k+n-1 \\
s
\end{array}\right)\left(\begin{array}{c}
l+n-1 \\
r
\end{array}\right) f^{(r)} g^{(s)},
$$

where

$$
f^{(r)}=\partial_{z}^{r} f, \quad \partial_{z} f=\left(\partial_{x} f-i \partial_{y} f\right) / 2 .
$$

H. Cohen proved in [1, Theorem 7.1] that the operation [_, $]_{n}^{R C}$ on the algebra $\mathcal{H} o l(\mathbb{H})\left[X^{-1}, X\right]$ is $S L(2, \mathbb{R})$-equivariant.

\section{Deformations}

A deformation of an associative $\mathbb{C}$-algebra $(A, m: A \otimes A \rightarrow A)$ is a $\mathbb{C}$-bilinear map

$$
\mu: A \times A \rightarrow A[[\hbar]], \quad \mu(a, b)=\sum_{n=0}^{\infty} \hbar^{n} \mu_{n}(a, b)
$$

such that

$$
\mu_{0}(a, b)=m(a \otimes b)=a b, \quad \quad \mu(1, a)=a=\mu(a, 1),
$$

and the $\mathbb{C}[[\hbar]]$-bilinear map $\tilde{\mu}: A[[\hbar]] \times A[[\hbar]] \rightarrow A[[\hbar]]$, which extends $\mu$ by $\mathbb{C}[\hbar]$-bilinearity and $\hbar$-adic continuity, is associative.

Let $\mathfrak{a} \subset \operatorname{Der} A$ be an abelian $\mathbb{C}$-subalgebra of the Lie $\mathbb{C}$-algebra of derivations of $A$. View an element

$$
P=\sum_{i=1}^{l} \xi_{i} \otimes \eta_{i} \in \mathfrak{a} \otimes_{\mathbb{C}} \mathfrak{a}
$$


as a $\mathbb{C}$-linear operator $A^{\otimes 2} \rightarrow A^{\otimes 2}$. It is well-known that

$$
a \star_{P} b \equiv \mu_{P}(a, b)=m \exp (\hbar P) \cdot(a \otimes b)=\sum_{n=0}^{\infty} \frac{\hbar^{n}}{n !} m P^{n} \cdot(a \otimes b)
$$

is a deformation of $A$. An example is provided by the Moyal deformation of $A=\mathcal{H}$ ol $\left(\mathbb{C}^{2}\right), \mathbb{C}^{2}=\{(q, p)\}, P=M=\partial_{p} \otimes \partial_{q}-\partial_{q} \otimes \partial_{p}$. The point of this note is to show that the Rankin-Cohen brackets give a deformation of the algebra $\mathcal{H}$ ol $(\mathbb{H})[X]$, related to the Moyal deformation.

Following a remark of Eholzer, Zagier noticed in [12] that many identities involving operations $[,]_{n}^{R C}$ follow from the statement that these form a deformation of the algebra of modular forms. This was further elaborated by P. Cohen, Manin, Zagier [2], where they show that the deformed algebra of modular forms is isomorphic to certain algebra of invariant pseudodifferential operators.

Connes and Moscovici discovered certain Hopf algebra $\mathcal{H}_{1}$ during their work on foliations [3]. They described also its action [4] on the algebra of modular forms from which a deformation of the latter is obtained. Moreover the Rankin-Cohen deformation generalizes to a universal deformation formula of $\mathcal{H}_{1}$ as shown by Tang and Yao [11]. These results are reviewed in [9].

Our proof of the main result is concise. It is most close to the proof by V. Ovsienko [7] with the difference that he looks for a symplectomorphism whereas we find an open embedding of $\mathbb{H} \times \mathbb{C}^{\times}$into $\mathbb{C}^{2}$, compatible with the Poisson structure.

\section{RANKIN-COHEN BRACKETS AS DEFORMATION}

Consider the open embedding

$$
\Psi=\left(\mathbb{H} \times \mathbb{C}^{\times} \hookrightarrow \mathbb{C} \times \mathbb{C}^{\times} \stackrel{\psi}{\cong} \mathbb{C} \times \mathbb{C}^{\times} \hookrightarrow \mathbb{C}^{2}\right),
$$

where $\psi(z, X)=\left(z X^{-1}, X^{-1}\right)=(q, p)$. Vector field $\partial_{p}$ (resp. $\left.\partial_{q}\right)$ on $\mathbb{C}^{2}$ is lifted along $\Psi$ to vector field $\xi=-X^{2} \partial_{X}-z X \partial_{z}\left(\right.$ resp. $\left.\eta=X \partial_{z}\right)$ on $\mathbb{H} \times \mathbb{C}^{\times}$. Thus,

is lifted to

$$
M=\partial_{p} \otimes \partial_{q}-\partial_{q} \otimes \partial_{p}
$$

$$
P=R C=\xi \otimes \eta-\eta \otimes \xi
$$

and $\xi$ and $\eta$ commute. Hence,

$$
F \star_{R C} G=m \exp (\hbar R C) .(F \otimes G)=\sum_{n=0}^{\infty} \frac{\hbar^{n}}{n !} m(R C)^{n} \cdot(F \otimes G)
$$

is a deformation of $\mathcal{H o l}\left(\mathbb{H} \times \mathbb{C}^{\times}\right)$. 
Theorem 3.1. Let $k, l \in \mathbb{Z}, n \in \mathbb{N}$. Assume that one of the following conditions holds:

- $k>0$;

- $l>0$;

- $k, l \leqslant 0$ and $n<\max \{1-k, 1-l\}$;

- $k, l \leqslant 0, n>1-k-l$.

Then for all $f, g \in \mathcal{H o l}(\mathbb{H})$ and $F=X^{k} f, G=X^{l} g$ we have

$$
(n !)^{-1} m(R C)^{n} \cdot(F \otimes G)=[F, G]_{n}^{R C} .
$$

Proof. The embedding $\Psi: \mathbb{H} \times \mathbb{C}^{\times} \hookrightarrow \mathbb{C}^{2}$ is $S L(2, \mathbb{R})$-equivariant, where the left action on $\mathbb{C}^{2}=\{(q, p)\}$ is the standard action of matrices on vectors. The mapping

$$
M=\partial_{p} \otimes \partial_{q}-\partial_{q} \otimes \partial_{p} \in \operatorname{End}_{\mathbb{C}}\left(\mathcal{H o l}\left(\mathbb{C}^{2}\right) \otimes \mathcal{H} \text { ol }\left(\mathbb{C}^{2}\right)\right)
$$

commutes with the action of $S L(2, \mathbb{R})$, or, equivalently, of the Lie algebra $\mathfrak{s l}(2, \mathbb{R})$. Hence, the Moyal deformation is $S L(2, \mathbb{R})$-equivariant. This implies and can be checked directly that

$$
R C=\xi \otimes \eta-\eta \otimes \xi \in \operatorname{End}_{\mathbb{C}}\left(\mathcal{H} o l\left(\mathbb{H} \times \mathbb{C}^{\times}\right) \otimes \mathcal{H} o l\left(\mathbb{H} \times \mathbb{C}^{\times}\right)\right)
$$

commutes with the action of $\mathfrak{s l}(2, \mathbb{R})$ and $S L(2, \mathbb{R})$. Thus,

$$
\star_{R C}: \mathcal{H o l}\left(\mathbb{H} \times \mathbb{C}^{\times}\right) \otimes \mathcal{H o l}\left(\mathbb{H} \times \mathbb{C}^{\times}\right) \rightarrow \mathcal{H} \text { ol }\left(\mathbb{H} \times \mathbb{C}^{\times}\right)[[\hbar]]
$$

is a homomorphism of $S L(2, \mathbb{R})$-modules. Accordingly to El Gradechi [5, Proposition 3.11] if the hypotheses on $(k, l, n)$ hold, then there is only 1-dimensional vector space of $S L(2, \mathbb{R})$-equivariant bidifferential operators

$$
\left(\mathcal{H o l}(\mathbb{H}),\left.\right|_{k}\right) \otimes\left(\mathcal{H o l}(\mathbb{H}),\left.\right|_{l}\right) \rightarrow\left(\mathcal{H} o l(\mathbb{H}),\left.\right|_{k+l+2 n}\right)
$$

Both maps

$$
f \otimes g \mapsto(n !)^{-1} m(R C)^{n} \cdot\left(X^{k} f \otimes X^{l} g\right), \quad f \otimes g \mapsto\left[X^{k} f, X^{l} g\right]_{n}^{R C}
$$

belong to this space, therefore, they are proportional. One checks that the proportionality constant is 1 . In fact, evaluate both operators on the following $f \otimes g$.

If $k=l=n=0$, take $f=g=1$.

If $k>0$ or $k<0, k \leqslant l \leqslant 0, n<1-k$, take $f=1, g=z^{n}$.

If $l>0$ or $l<0, l \leqslant k \leqslant 0, n<1-l$, take $f=z^{n}, g=1$.

If $k, l \leqslant 0$ and $n>1-k-l$ choose $r, s \in \mathbb{N}$, such that $r+s=n, r+k>0$ and $s+l>0$, and take $f(z)=z^{r}$ and $g(z)=z^{s}$. (Hint: use coordinates $(q, p)$ to make the computations easier $)$. 
Corollary 3.2. The Rankin-Cohen deformation $\star_{R C}$ restricted to $A^{\otimes 2}$, $A=\mathcal{H o l}(\mathbb{H})[X]$ coincides with the map

$$
A \otimes A \rightarrow A[[\hbar]], \quad X^{k} f \otimes X^{l} g \mapsto \sum_{n=0}^{\infty} \hbar^{n}\left[X^{k} f, X^{l} g\right]_{n}^{R C} .
$$

Proof. For all $(k, l, n) \in \mathbb{N}^{3}$ the statement follows from Theorem 3.1 except for $(k, l, n)=(0,0,1)$. In the latter case $[f, g]_{1}=0=m(R C)(f \otimes g)$ for all $f, g \in \mathcal{H o l}(\mathbb{H})$.

\section{REFERENCES}

[1] Henri Cohen. Sums involving the values at negative integers of $L$-functions of quadratic characters. Math. Ann., 217(3):271-285, 1975.

[2] Paula Beazley Cohen, Yuri I. Manin, Don Zagier. Automorphic pseudodifferential operators. In Algebraic aspects of integrable systems, volume 26 of Progr. Nonlinear Differential Equations Appl., 17-47. Birkhäuser Verlag, Boston, MA, 1997.

[3] Alain Connes, Henri Moscovici. Hopf algebras, cyclic cohomology and the transverse index theorem. Comm. Math. Phys., 198(1):199-246, 1998.

[4] Alain Connes, Henri Moscovici. Rankin-Cohen brackets and the Hopf algebra of transverse geometry. Mosc. Math. J., 4(1):111-130, 311, 2004.

[5] Amine M. El Gradechi. The Lie theory of the Rankin-Cohen brackets and allied bidifferential operators. Adv. Math., 207(2):484-531, 2006.

[6] Paul A. Gordan. Vorlesungen über Invariantentheorie. Teubner, Leipzig, 1885.

[7] Valentin Ovsienko. Exotic deformation quantization. J. Differential Geom., 45(2):390406, 1997.

[8] Robert Alexander Rankin. The construction of automorphic forms from the derivatives of given forms. The Michigan Mathematical Journal, 4(2):181-186, 1957.

[9] Richard Rochberg, Xiang Tang, Yijun Yao. A survey on Rankin-Cohen deformations. In Perspectives on noncommutative geometry. Proceedings of the noncommutative geometry workshop, Fields Institute, Toronto, Canada, May 27-31, 2008, 133-151. Providence, RI: American Mathematical Society (AMS); Toronto: The Fields Institute for Research in Mathematical Sciences, 2011.

[10] Goro Shimura. Introduction to the arithmetic theory of automorphic functions, volume 11 of Publ. of the Math. Soc. of Japan. Iwanami Shoten, Publishers, Tokyo, 1971. Kanô Memorial Lectures, No. 1.

[11] Xiang Tang, Yi-Jun Yao. A universal deformation formula for $\mathcal{H}_{1}$ without projectivity assumption. Journal of Noncommutative Geometry, 3(2):151-179, 2009.

[12] Don Zagier. Modular forms and differential operators. Proc. Indian Acad. Sci. Math. Sci., 104(1):57-75, 1994. K. G. Ramanathan memorial issue.

Received: January 15, 2018, accepted: June 5, 2018.

Volodymyr Lyubashenko

Institute of Mathematics of NAS of Ukraine, 3 Tereshchenkivska st., Kyiv, 01004, UKRAINE

Email: lub@imath.kiev.ua

ORCID: orcid.org/0000-0002-3480-1514 